\title{
Nanotechnology in Agriculture: Which Innovation Potential Does It Have?
}

\author{
Leonardo F. Fraceto ${ }^{1 *}$, Renato Grillo ${ }^{2}$, Gerson A. de Medeiros ${ }^{1}$, Viviana Scognamiglio ${ }^{3}$, \\ Giuseppina Rea ${ }^{3}$ and Cecilia Bartolucci ${ }^{3,4}$
}

${ }^{1}$ Department of Environmental Engineering, São Paulo State University, Sorocaba, Brazil, ${ }^{2}$ Center of Natural and Human Sciences, Federal University of ABC, Santo André, Brazil, ${ }^{3}$ Institute of Crystallography, National Research Council, Rome, Italy, ${ }^{4}$ Science and Technology Foresight, National Research Council, Rome, Italy

OPEN ACCESS

Edited by:

Md Ahmaruzzaman, National Institute of Technology

Silchar, India

Reviewed by:

Matteo Guidotti,

Institute of Molecular Science and

Technologies - National Research

Council, Italy

Alexei Lapkin,

University of Cambridge, UK

*Correspondence:

Leonardo F. Fraceto

leonardo@sorocaba.unesp.br

Specialty section:

This article was submitted to Green and Environmental Chemistry, a section of the journal

Frontiers in Environmental Science

Received: 22 January 2016 Accepted: 07 March 2016

Published: 22 March 2016

Citation:

Fraceto LF, Grillo R, de Medeiros GA,

Scognamiglio V, Rea G and

Bartolucci C (2016) Nanotechnology

in Agriculture: Which Innovation

Potential Does It Have?

Front. Environ. Sci. 4:20.

doi: 10.3389/fenvs.2016.00020
Recent scientific data indicate that nanotechnology has the potential to positively impact the agrifood sector, minimizing adverse problems of agricultural practices on environment and human health, improving food security and productivity (as required by the predicted rise in global population), while promoting social and economic equity. In this context, we select and report on recent trends in nanomaterial-based systems and nanodevices that could provide benefits on the food supply chain specifically on sustainable intensification, and management of soil and waste. Among others, nanomaterials for controlled-release of nutrients, pesticides and fertilizers in crops are described as well as nanosensors for agricultural practices, food quality and safety.

Keywords: nanotechnology, nanodelivery systems, nanosensors, sustainable agriculture

\section{CURRENT AND FUTURE TRENDS}

Recently, a wide range of potential applications of nanotechnology has been envisaged also in agriculture, leading to intense research at both academic and industrial levels (Chen and Yada, 2011; Dasgupta et al., 2015; Parisi et al., 2015). Indeed, the unique properties of materials at nanoscale make them suitable candidates for the design and development of novel tools in support of a sustainable agriculture. Some of the main applications of these nanotools in agriculture are reported in the following paragraphs, and schematically drawn in Figure 1.

\section{Systems for Sustainable Intensification in Agriculture}

Sustainable intensification is a concept related to a production system aiming to increase the yield without adverse environmental impact while cultivating the same agricultural area (The Royal Society, 2009). This paradigm provides a framework to evaluate the selection of the best combination of approaches to agricultural production considering the influence of the current biophysical, social, cultural, and economic situation (Garnett and Godfray, 2012). In this context, novel nanomaterials based on the use of inorganic, polymeric, and lipid nanoparticles, synthesized by exploiting different techniques (e.g., emulsification, ionic gelation, polymerization, oxydoreduction, etc) have been developed to increase productivity (Figure 1A).

They can find application, as an example, for the development of intelligent nanosystems for the immobilization of nutrients and their release in soil. Such systems have the advantage to minimize leaching, while improving the uptake of nutrients by plants, and to mitigate eutrophication by reducing the transfer of nitrogen to groundwater (Liu and Lal, 2015). Furthermore, it is noteworthy to mention that nanomaterials could also be exploited to improve structure and function of pesticides by increasing solubility, enhancing resistance against hydrolysis 


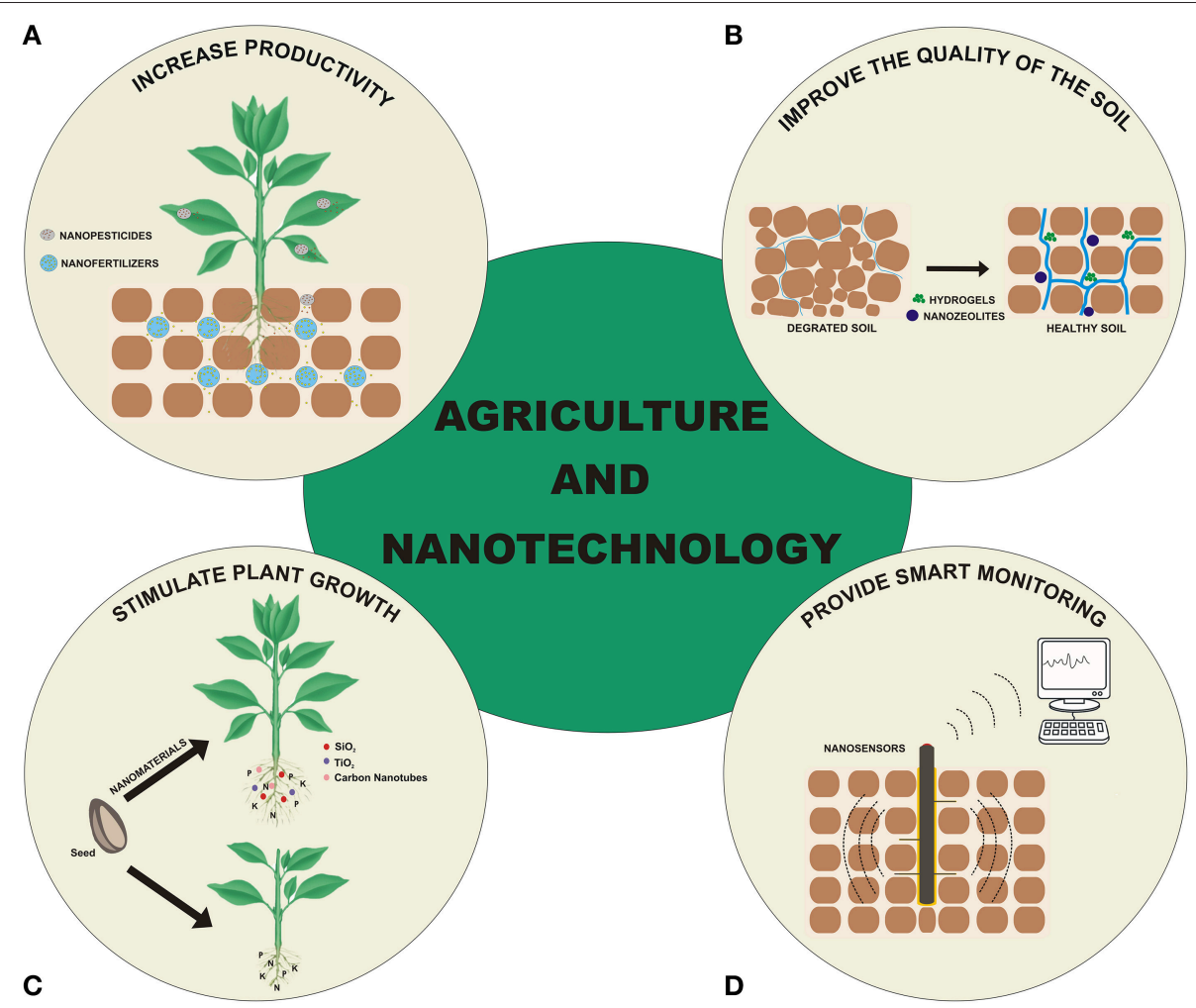

FIGURE 1 | Potential applications of nanotechnology in agriculture. (A) Increase the productivity using nanopesticides and nanofertilizers; (B) Improve the quality of the soil using nanozeolites and hydrogels; (C) Stimulate plant growth using nanomaterials $\left(\mathrm{SiO}_{2}, \mathrm{TiO}_{2}\right.$, and carbon nanotubes); (D) Provide smart monitoring using nanosensors by wireless communication devices.

and photodecomposition, and/or by providing a more specific and controlled-release toward target organisms (Mishra and Singh, 2015; Grillo et al., 2016; Nuruzzaman et al., 2016).

\section{Systems to Improve the Quality of the Soil}

Hydrogels, nanoclays, and nanozeolites have been reported to enhance the water-holding capacity of soil (Sekhon, 2014), hence acting as a slow release source of water, reducing the hydric shortage periods during crop season (Figure 1B). Applications of such systems are favorable for both agricultural purposes and reforestation of degraded areas. Organic e.g., such as polymer and carbon nanotubes and inorganic e.g., such as nano metals and metal oxides nanomaterials have also been used to absorb environmental contaminants (Khin et al., 2012), increasing soil remediation capacity and reducing times and costs of the treatments.

\section{Nanomaterials as Agents to Stimulate Plant Growth}

Carbon nanotubes and nanoparticles of $\mathrm{Au}, \mathrm{SiO}_{2}, \mathrm{ZnO}$, and $\mathrm{TiO}_{2}$ can contribute to ameliorate development of plants (Figure 1C), by enhancing elemental uptake and use of nutrients (Khot et al., 2012). However, the real impact of nanomaterials on plants depends on their composition, concentration, size, surface charge, and physical chemical properties, besides the susceptibility of the plant species (Ma et al., 2010; Lambreva et al.,
2015). The development of new protocols and the use of different analytical techniques (such as microscopy, magnetic resonance imaging, and fluorescence spectroscopy) could considerably contribute to understand the interactions between plants and nanomaterials.

\section{Nano-d for the Management of the Food Supply Chain}

Nanotechnology can find applications also in the development of analytical devices dedicated to the control of quality, bio/security, and safety not only in agriculture, but also along the food supply chain (Valdes et al., 2009). In this context, nanosensors represent a powerful tool with advanced and improved features, compared to existing analytical sensors and biosensors. Nanosensors are defined as analytical devices having at least one sensing dimension no greater than $100 \mathrm{~nm}$, fabricated for monitoring physico-chemical properties in places otherwise difficult to reach. Nanotubes, nanowires, nanoparticles, or nanocrystals are often used to optimize the signal transduction deriving by sensing elements in response to exposure to biological and chemical analytes having similar size. They have unique surface chemistry, distinct thermal, electrical and optical properties, useful to enhance sensitivities, reduce response times, and improve detection limits, and can be used in multiplexed systems (Aragay et al., 2010; Yao et al., 2014). Considering the huge 
amount of research in this area, real applications of nanosensors for field analysis are unexpectedly scarce, implying the potential for a new market. In this perspective, nanotechnologies could enhance biosensor performance to allow real applications in agrifood (Figure 1D). Indeed, thanks to important progresses in nanofabrication, laboratory analytical techniques, such as surface plasmon resonance, mass spectrometry, chromatography, or electrophoresis chips, can support the development of viable sensor components. However, the real need of the market is the realization of automated embedded systems, which integrate biosensing components with micro/nanofluidics, data management hardware, and remote control by wireless networks. This is a key issue for nanotechnology, which can provide the decisive approaches as well as novel nanomaterials for the realization of biosensing devices (Scognamiglio, 2013). Indeed, as described by Mousavi and Rezaei (2011) "Nanosensors help farmers in maintaining farm with precise control and report timely needs of plants." Thus, it will be mandatory to address research efforts to the development of nanosensors to aid decision-making in crop monitoring, accurate analysis of nutrients and pesticides in soil, or for maximizing the efficiency of water use for a smart agriculture. In this context, nanosensors could demonstrate their potential in managing all the phases of the food supply chain, from crop cultivation and harvesting to food processing, transportation, packaging, and distribution (Scognamiglio et al., 2014). Among them, nanosensors for dynamic measurement of soil parameters ( $\mathrm{pH}$ and nutrients, residual pesticides in crop and soil, and soil humidity) detection of pathogens and prediction of nitrogen uptake are only few examples to foster a sustainable farming (Bellingham, 2011). Specifically, nanosensor systems can be developed to monitor the presence of pests, pathogens or pesticides in order to better tune the amount of insecticides to be employed for crop productivity management, since they show higher sensitivity and specificity compared to the "traditional" sensors. For example, controlled release mechanisms via nanoscale carriers monitored by nanosensors integrated in platforms employing wireless signals, will avoid overdose of agricultural chemicals and minimize inputs of fertilizers and pesticides during the course of cultivations, improving productivity, and reducing waste. Networks of nanosensors located throughout cultivated fields will assure a real time and comprehensive monitoring of the crop growth, furnishing effective high quality data for best management practices (El Beyrouthya and El Azzi, 2014).

The automation of irrigation systems is also a crucial requirement of smart agriculture, mainly in a scenario of water shortage. In this regard, sensor technology has the potential to maximize the efficiency of water use. Nanosensors estimating soil water tension in real-time may be coupled with autonomous irrigation controllers. This feature allows a sustainable irrigation management based on drying soil, otherwise an approach too difficult for farmers because it involves evaluation of climate and crop growth aspects of high complexity (de Medeiros et al., 2001).

Furthermore, nanosensors find also application in fast, sensitive, and cost-effective detection of different targets to ensure food quality, safety, freshness, authenticity, and traceability along the entire food supply chain. Surely, nanosensors represent one of the emerging technologies challenging the assessment of food quality and safety, being able to provide smart monitoring of food components (e.g., sugars, amino acid, alcohol, vitamins, and minerals) and contaminants (e.g., pesticides, heavy metals, toxins, and food additives). Food quality and food safety control represents a crucial effort not only to obtain a healthy food, but also to avoid huge waste of food products. The potential of nanosensor can also be demonstrated by the last trends on intelligent or smart packaging to monitor the freshness properties of food, and check the integrity of the packages during transport, storage, and display in markets (Vanderroost et al., 2014). Many intelligent packaging involve nanosensors as monitoring systems to measure physical parameters (humidity, $\mathrm{pH}$, temperature, light exposure), to reveal gas mixtures (e.g., oxygen and carbon dioxide), to detect pathogens and toxins, or to control freshness (e.g., ethanol, lactic acid, acetic acid) and decomposition (e.g., putrescine, cadaverine).

\section{IDENTIFICATION OF GAPS AND OBSTACLES}

Despite considerable advances in identifying possible applications of nanotechnology in agriculture, many issues remain to be resolved in the near future before this technology may make significant contributions to the area of agriculture. Some of the main aspects that require further attention are: (i) development of specific hybrid carriers for delivering active agents including nutrients, pesticides and fertilizers in order to maximize their efficiency following the principles of green chemistry and environmental sustainability (De Oliveira et al., 2014); (ii) design of processes easily upscalable at industrial level, (iii) comparison of effects of nanoformulations/nanosystems with existing commercial products, in order to demonstrate real practical advantages; (iv) acquisition of knowledge and developments of methods for risk and life-cycle assessment of nanomaterials, nanopesticides, nanofertilizers, as well as assessment of the impacts (e.g., phytotoxic effects) on non-target organisms e.g., other plants, soil microbiota, and bees; (v) advances in the regulations about the use of nanomaterials (Amenta et al., 2015). In this context, the progress made in the exploitation of nanopesticides (such as atrazine) represents a useful case study to identify the main parameters necessary to predict the behavior of nanomaterials in the environment (Grillo et al., 2012). In the study of the atrazine-nanopesticide system care was taken to understand the mechanisms of interaction with both target, mustard (Oliveira et al., 2015a), and non-target organisms, maize (Oliveira et al., 2015b), and risk-assessment analyses were also considered (Kah et al., 2014). However, future case studies are necessary in order to address the safety of workers and consumers with respect to food produced using nanomaterials and nanoparticles (Figure 2).

The implementation of nanotechnology in agriculture requires also the development of techniques capable of quantifying engineered nanoparticles at the concentrations present in different environmental compartments (Sadik et al., 


\section{Nanopesticides: atrazine case}

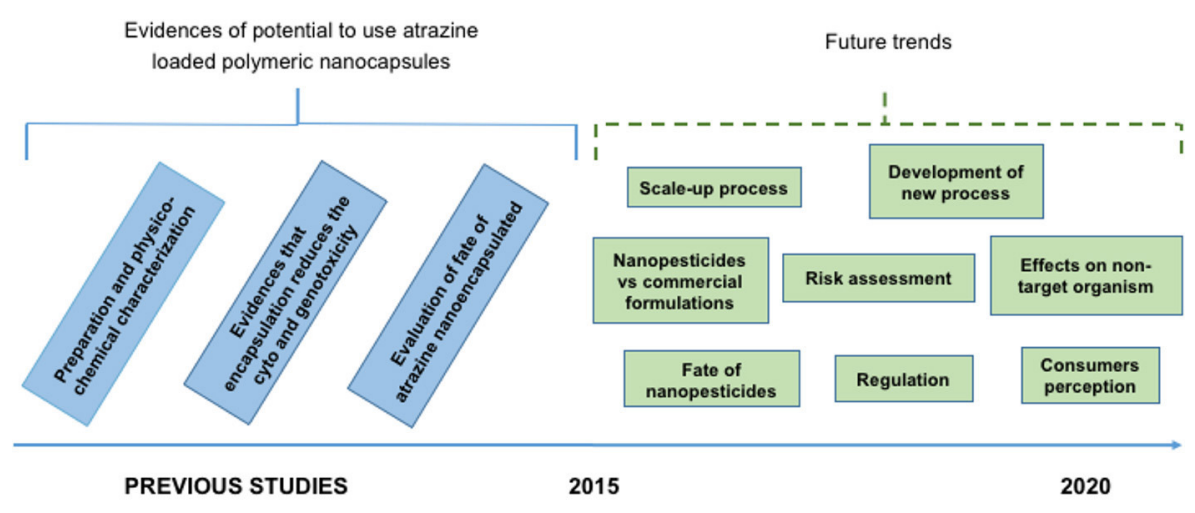

FIGURE 2 | Timescale for developments in atrazine nanopesticide.

2014). Currently available methods are not always adequate to understand the dynamics of nanomaterials in the environment, their interactions with target and non-target organisms, or the occurrence of synergistic effects. These methodological advances allow a life cycle assessment of the new developed nanomaterials (Kookana et al., 2014; Parisi et al., 2015). Besides, studies on methodologies able to assess possible arise of resistance mechanisms to nanomaterials by target organisms should be undertaken. As a whole, the newly developed analytical methodologies would support predictive models to characterize, localize, and quantify engineered nanomaterials in the environments. In this context, knowledge exchange among scientists from different research fields would be essential (Malysheva et al., 2015).

\section{CONCLUSIONS}

In conclusion, considering the great challenges we will be facing, in particular due to a growing global population and climate change, the application of nanotechnologies as well as the introduction of nanomaterials in agriculture, potentially can greatly contribute to address the issue of sustainability. In fact, the efficient use of fertilizers and pesticides can be enhanced by the use of nanoscale carriers and compounds, reducing the amount to be applied without impairing productivity. Nanotechnologies can also have an impact on the reduction of waste, both contributing to a more efficient production as well as to the

\section{REFERENCES}

Amenta, V., Aschberger, K., Arena, M., Bouwmeester, H., Moniz, F. B., Brandhoff, P., et al. (2015). Regulatory aspects of nanotechnology in the agri/feed/food sector in EU and non-EU countries. Regul. Toxicol. Pharmacol. 73, 463-476. doi: 10.1016/j.yrtph.2015.06.016

Aragay, G., Pons, J., Ros, J., and Merkoci, A. (2010). Aminopyrazole-based ligand induces gold nanoparticle formation and remains available for heavy metal ions sensing. A simple "mix and detect" approach. Langmuir 26, 10165-10170. doi: $10.1021 / \mathrm{la} 100288 \mathrm{~s}$ reuse of waste, while nanosensors technology can encourage the diffusion of precision agriculture, for an efficient management of resources, including energy (FAO and WHO, 2013).

However, as with the application of all new technologies, there is the need to perform a reliable risk-benefit assessment, as well as a full cost accounting evaluation. In the case of nanotechnologies, this requires also the development of reliable methods for the characterization and quantification of nanomaterials in different matrices and for the evaluation of their impact on the environment (Servin and White, 2016) as well as on human health (EFSA Scientific Committee, 2011). Furthermore, it is very important to engage all stakeholders, including nongovernmental and consumer associations, in an open dialogue to acquire consumer acceptance and public support for this technology.

\section{AUTHOR CONTRIBUTIONS}

All the authors participated in the drafting the manuscript and discussion of all topics related to this perspective manuscript.

\section{ACKNOWLEDGMENTS}

The authors would like to thank São Paulo Science Foundation (\#2013-12322-2 and 2015/26189-8), CNPq and CAPES. Also we would like to thanks Prof. H.B. Singh (Banaras Hindu University-India) for his critics to this paper. 
(Phaseolus vulgaris L.). Agric. Water Manage. 49, 211-224. doi: 10.1016/S03783774(00)00150-5

De Oliveira, J. L., Campos, E. V. R., Bakshi, M., Abhilash, P. C., and Fraceto, L. F. (2014). Application of nanotechnology for the encapsulation of botanical insecticides for sustainable agriculture: prospects and promises. Biotechnol. Adv. 32, 1550-1561. doi: 10.1016/j.biotechadv.2014. 10.010

EFSA Scientific Committee, (2011). Scientific Opinion on Guidance on the risk assessment of the application of nanoscience and nanotechnologies in the food and feed chain. EFSA J. 9:2140. doi: 10.2903/j.efsa.2011. 2140

El Beyrouthya, M., and El Azzi, D. (2014). Nanotechnologies: novel solutions for sustainable agriculture. Adv. Crop Sci. Technol. 2:e118. doi: 10.4172/2329$8863.1000 \mathrm{e} 118$

FAO, Food and Agriculture Organization of the United Nations and WHO, World Health Organization, (2013). State of the Art on the Initiatives and Activities Relevant to Risk Assessment and Risk Management of Nanotechnologies in the Food and Agriculture Sectors. Technical Paper, FAO and WHO, Rome.

Garnett, T., and Godfray, C. (2012). Sustainable Intensification in Agriculture. Navigating a Course Through Competing Food System Priorities, Food Climate Research Network and the Oxford Martin Programme on the Future of Food. University of Oxford, UK

Grillo, R., Abhilash, P. C., and Fraceto, L. F. (2016). Nanotechnology applied to bio-encapsulation of pesticides. J. Nanosci. Nanotechnol. 16, 1231-1234. doi: 10.1166/jnn.2016.12332

Grillo, R., Dos Santos, N. Z. P., Maruyama, C. R., Rosa, A. H., De Lima, R., and Fraceto, L. F., et al. (2012). Poly(epsilon-caprolactone)nanocapsules as carrier systems for herbicides: physico-chemical characterization and genotoxicity evaluation. J. Hazard. Mater. 231, 1-9. doi: 10.1016/j.jhazmat.2012. 06.019

Kah, M., Machinski, P., Koerner, P., Tiede, K., Grillo, R., Fraceto, L. F., et al. (2014). Analysing the fate of nanopesticides in soil and the applicability of regulatory protocols using a polymer-based nanoformulation of atrazine. Environ. Sci. Pollut. Res. Int. 21, 11699-11707. doi: 10.1007/s11356-0142523-6

Khin, M. M., Nair, A. S., Babu, V. J., Murugan, R., and Ramakrishna, S. (2012). A review on nanomaterials for environmental remediation. Energy Environ. Sci. 5, 8075-8109. doi: 10.1039/c2ee21818f

Khot, L. R., Sankaran, S., Maja, J. M., Ehsani, R., and Schuster, E. W. (2012). Applications of nanomaterials in agricultural production and crop protection: a review. Crop Prot. 35, 64-70. doi: 10.1016/j.cropro.2012. 01.007

Kookana, R. S., Boxall, A. B., Reeves, P. T., Ashauer, R., Beulke, S., Chaudhry, Q., et al. (2014). Nanopesticides: guiding principles for regulatory evaluation of environmental risks. J. Agric. Food Chem. 62, 4227-4240. doi: 10.1021/jf50 $0232 \mathrm{f}$

Lambreva, M. D., Lavecchia, T., Tyystjärvi, E., Antal, T. K., Orlanducci, S., Margonelli, A., et al. (2015). Potential of carbon nanotubes in algal biotechnology. Photosyn. Res. 125, 451-471. doi: 10.1007/s11120-0150168-z

Liu, R. Q., and Lal, R. (2015). Potentials of engineered nanoparticles as fertilizers for increasing agronomic productions. Sci. Total Environ. 514, 131-139. doi: 10.1016/j.scitotenv.2015.01.104

Ma, X., Geiser-Lee, J., Deng, Y., and Kolmakov, A. (2010). Interactions between engineered nanoparticles (ENPs) and plants: phytotoxicity, uptake and accumulation. Sci. Total Environ. 408, 3053-3061. doi: 10.1016/j.scitotenv.2010.03.031

Malysheva, A., Lombi, E., and Voelcker, N. H. (2015). Bridging the divide between human and environmental nanotoxicology. Nat. Nanotechnol. 10, 835-844. doi: $10.1038 /$ nnano.2015.224
Mishra, S., and Singh, H. B. (2015). Biosynthesized silver nanoparticles as a nanoweapon against phytopathogens: exploring their scope and potential in agriculture. Appl. Microbiol. Biotechnol. 99, 1097-1107 doi: 10.1007/s00253014-6296-0

Mousavi, S. R., and Rezaei, M. (2011). Nanotechnology in agriculture and food production. J. Appl. Environ. Biol. Sci. 1, 414-419.

Nuruzzaman, M., Rahman, M. M., Liu, Y., and Naidu, R. (2016). Nanoencapsulation, nano-guard for pesticides: a new window for safe application. J. Agric. Food Chem. 64, 1447-1483. doi: 10.1021/acs.jafc. $5 \mathrm{~b} 05214$

Oliveira, H. C., Stolf-Moreira, R., Martinez, C. B. R., Grillo, R., De Jesus, M. B. and Fraceto, L. F. (2015a). Nanoencapsulation enhances the post-emergence herbicidal activity of atrazine against mustard plants. PLoS ONE 10:e0132971. doi: 10.1371/journal.pone.0132971

Oliveira, H. C., Stolf-Moreira, R., Martinez, C. B. R., Sousa, G. F. M., Grillo, R., De Jesus, M. B., et al. (2015b). Evaluation of the side effects of poly(epsiloncaprolactone) nanocapsules containing atrazine toward maize plants. Front. Chem. 3:61. doi: 10.3389/fchem.2015.00061

Parisi, C., Vigani, M., and Rodriguez-Cerezo, E. (2015). Agricultural nanotechnologies: what are the current possibilities? Nano Today 10, 124-127. doi: 10.1016/j.nantod.2014.09.009

The Royal Society (2009). Reaping the Benefits: Science and the Sustainable Intensification of Global Agriculture, London: The Royal Society.

Sadik, O. A., Du, N., Kariuki, V., Okello, V., and Bushlyar, V. (2014). Current and emerging technologies for the characterization of nanomaterials. ACS Sustain. Chem. Eng. 2, 1707-1716. doi: 10.1021/sc500175v

Scognamiglio, V. (2013). Nanotechnology in glucose monitoring: advances and challenges in the last 10 years. Biosens. Bioelectron. 47, 12-25. doi: 10.1016/j.bios.2013.02.043

Scognamiglio, V., Arduini, F., Palleschi, G., and Rea, G. (2014). Biosensing technology for sustainable food safety. Trac-Trends Anal. Chem. 62, 1-10. doi: 10.1016/j.trac.2014.07.007

Sekhon, B. S. (2014). Nanotechnology in agri-food production: an overview. Nanotechnol. Sci. Appl. 7, 31-53. doi: 10.2147/NSA. S39406

Servin, A. D., and White, J. C. (2016). Nanotechnology in agriculture: next steps for understanding engineered nanoparticle exposure and risk. NanoImpact 1, 9-12. doi: 10.1016/j.impact.2015.12.002

Valdes, M. G., Gonzalez, A. C. V., Calzon, J. A. G., and Diaz-Garcia, M. E. (2009). Analytical nanotechnology for food analysis. Microchimica Acta 166, 1-19. doi: 10.1007/s00604-009-0165-Z

Vanderroost, M., Ragaert, P., Devlieghere, F., and De Meulenaer, B. (2014). Intelligent food packaging: the next generation. Trends Food Sci. Technol. 39, 47-62. doi: 10.1016/j.tifs.2014.06.009

Yao, J., Yang, M., and Duan, Y. X. (2014). Chemistry, biology, and medicine of fluorescent nanomaterials and related systems: new insights into biosensing, bioimaging, genomics, diagnostics, and therapy. Chem. Rev. 114, 6130-6178. doi: $10.1021 / \mathrm{cr} 200359 \mathrm{p}$

Conflict of Interest Statement: The authors declare that the research was conducted in the absence of any commercial or financial relationships that could be construed as a potential conflict of interest.

Copyright (๑ 2016 Fraceto, Grillo, de Medeiros, Scognamiglio, Rea and Bartolucci. This is an open-access article distributed under the terms of the Creative Commons Attribution License (CC BY). The use, distribution or reproduction in other forums is permitted, provided the original author(s) or licensor are credited and that the original publication in this journal is cited, in accordance with accepted academic practice. No use, distribution or reproduction is permitted which does not comply with these terms. 